\title{
Learning Styles/Preferences Among Medical Students: Kinesthetic Learner's Multimodal Approach to Learning Anatomy
}

\author{
Jessa E. Hernandez ${ }^{1,2} \cdot$ Nagaswami Vasan $^{1}$ (D) $\cdot$ Susan Huff $^{3} \cdot$ Cheryl Melovitz-Vasan $^{1}$ \\ Published online: 27 August 2020 \\ (C) International Association of Medical Science Educators 2020
}

\begin{abstract}
Numerous learning styles, schemes, and models are described in the literature. Most common are VARK (visual, auditory, $\mathrm{read} /$ write, kinesthetic) model of learning style and Kolb's experiential learning. Since the concept of learning style was first described, educational psychologists and medical educators have debated its validity. Notwithstanding these disagreements, VARK model is the one most utilized by teachers and students. This article describes how medical students with different learning styles learn anatomy and integrate multiple learning styles (multimodal) to achieve the learning goals and focuses on the approach taken by kinesthetic learners. In addition to clay modeling, drawing, and sketching, kinesthetic learners adopted "crochet" to create a three-dimensional (3-D) conceptual model that helped them mentally visualize the structures in situ. From the lectures and cadaveric dissection, a kinesthetic learner could create a 3-D mental model. However, by "crochet" and clay modeling, kinesthetic learners are able to gain broader visuospatial understanding.
\end{abstract}

Keywords Learning anatomy $\cdot$ Learning styles $\cdot$ Learning preferences $\cdot$ Kinesthetic learners $\cdot$ VARK's modalities $\cdot$ Multimodal learning approach

\section{Introduction}

There are number of learning styles, schemes, and models described in the literature; one review listed 71 different schemes [1]. Most commonly used are VARK model of learning style and Kolb's experiential learning [2, 3]. Kolb's learning style inventory (LSI) [3], perhaps one of the best-known and most widely used questionnaires, uses Kolb's learning styles to help students identify their learning style. It also

This study was presented as a poster in the session on "Anatomy Education-Learning Strategy", American Association of Anatomists, EB Annual Meeting, April 2018, San Diego, CA.

Nagaswami Vasan

vasan@rowan.edu

1 Department of Biomedical Sciences, Cooper Medical School of Rowan University, 401 South Broadway, Camden, NJ 08103, USA

2 Inspira Health Network, Vineland, NJ, USA

3 The Office of Medical Education, Cooper Medical School of Rowan University, 401 South Broadway, Camden, NJ 08103, USA provides information on how educators can use this information to best serve students, as well as possible strategies for accommodating different learning styles. The effective learner relies on four different learning modes: concrete experience (CE), reflective observation (RO), abstract conceptualization (AC), and active experimentation (AE). S/he must be able to involve her/himself fully, openly, and without bias in new experiences (CE); reflect on and observe these experiences from many perspectives (RO); create concepts that integrate observations into logically sound theories (AC); and use these theories to make decisions and solve problem (AE).

Since VARK learning style was first described in 1992 [2], educational psychologists and medical educators have debated its validity $[4,5]$. Despite the disagreement, VARK model is the one most widely accepted by students, teachers, and researchers. The term "learning style" describes an individual's preferred method of gathering, processing, interpreting, organizing, and analyzing information [6]. The VARK model [2] profiles learners, based on the sensory methods they use to assimilate information. VARK is an acronym for the visual (V), auditory (A), read/write (R), and the kinesthetic (K) sensory modalities. Visual learners prefer depictions of information as figures and charts. Auditory learners prefer to hear the 
information as lectures and discussions. Read/write learners prefer information presented as text-based. Kinesthetic learners prefer concrete experiences that connect the material to reality [2]. However, most medical students have a multimodal approach to learning. The Approaches and Study Skills Inventory for Students (ASSIST) aids in the understanding of students' preference in adopting any or all of the deep, surface, or strategic approaches for learning [7].

To guide students into understanding the complex modern health care delivery system, undergraduate medical education curriculum, while becoming innovative, should also acknowledge and support students with different learning styles and preferences. Learning anatomy involves the use of many components: cadaveric dissection, embryology (normal and anomalous), radiographic images, and didactic material. Testing largely includes clinical scenarios. Thus, learning naturally becomes multimodal, compared other basic sciences like biochemistry and others. Medical students use a multimodal approach (visual, aural, reading, and kinesthetic) to master various subjects and approaches vary between the preclinical and clinical phases of their training [8]. Medical students who consider themselves visual (V), auditory (A), read/ write $(\mathrm{R})$, or kinesthetic $(\mathrm{K})$ sensory learners are, in reality, bi-, tri-, or multimodal learners [9].

Preclinical medical curriculum includes basic sciences such as anatomy, physiology, pharmacology, pathology, and biochemistry. While most, if not all, of these courses utilize primarily didactic presentations with a few small group activities, anatomy course includes embryology, radiographic images, and mandatory cadaveric dissections. Students adopt a variety of study strategies, including VARK and surface, deep, and strategic approaches, during preclinical training to learn the material. Some studies relate to the question of "learning styles and academic performance" [10-12].

Traditionally, anatomy is taught in lectures, prosection, and cadaveric dissection. Lectures cater primarily to the auditory learner; associated printed presentations or handouts serve $\mathrm{read} / \mathrm{write}$ and possibly visual learners, as well. Prosection helps visual learners who are watching the expert and can target auditory learners who listen to explanations during the prosection. Dissection can target both visual and kinesthetic learners. The final teaching method is self-directed learning, which includes problem-based and computer-assisted learning. These techniques are also best for auditory learners, through group discussion. Computer-based learning can help visual learners, who use pictures and other visual aids, but this offers little to kinesthetic learners.

Although cadaver dissections target visual and kinesthetic learners, their use in medical school curriculum has been declining [13-15]. As costs increase and cadaver donation decreases, the use of cadavers in medical schools also decreases. Those schools that maintain cadaver dissection increase the size of their anatomy dissection groups, which, in turn, decreases the amount of concrete hands-on experience that each student gets per cadaver [13-15]. Efforts to resolve this issue have resulted in development of a tremendous amount of new technology that provides virtual cadavers to explore. Complete anatomy, e-Anatomy, HeadNeckBrainSpine.com, the interactive atlas of human anatomy, and virtual 3D anatomy models are some of these innovative resources; however, educators must find another solution to target kinesthetic learners who get little benefit from technology, including, but not limited to, modeling, sketches, drawings, and crochet.

\section{Description}

Opened in 2009, admitting its first class in 2012, Cooper Medical School of Rowan University (CMSRU) is a fully accredited, 4-year allopathic medical school. The preclinical curriculum at CMSRU is both horizontally and vertically integrated and organ system-based. Importantly, CMSRU builds "self-directed learning" time into the daily schedule. Students can use this time in collaborative learning in small groups. Required "community service" time is also built into the curriculum. To satisfy this requirement, some students tutor, while others conduct learning enhancement activities. The first author's crochet, clay modeling, and drawing are examples of such activities. Does the drawing, crochet, and clay modeling increase the student work load? After speaking with many students, it seems the work load/time never crossed their mind. Numerous students attend hands-on (clay modeling, drawing, and crochet) sessions conducted by the first author (Jessa Hernandez), who herself just graduated from medical school. It seems students consider these activities as helpful in learning anatomy.

Anatomy is taught in every organ system course (module) in years 1 and 2 of the integrated curriculum and the time allotted for various organ system courses varies, taking into consideration the other basic sciences that are taught integratively. To teach anatomy, the curriculum includes didactic presentations, hands-on mandatory cadaveric dissection, small group active learning through case discussion, dedicated time for self-directed learning, radiographic images, and independent learning using prosections and anatomical models. While these approaches facilitate visual, auditory, and read/write learners, they offer limited support to kinesthetic learners. To facilitate "kinesthetic" and other multimodal learning, students have open access to the cadavers, prosections, anatomical models, and other materials. For kinesthetic learners, drawing, crochet, clay modeling, and the like provide students a way to translate a short-term visual to a long-term memory for easy retrieval when needed (exams or during clinical phase of their training). 
Bimodal didactic anatomy and embryology presentations include features to assist both visual and aural learners. During self-directed learning, students adopt a different approach, learning in small group through discussion, drawings, creating charts, clarification, and note taking. The hands-on approach of cadaveric dissection aids kinesthetic learners, who also reinforce their visual understanding through drawings, clay modeling, and crochet. A number of other kinesthetic learners utilize drawing sketches, stick figures, and body painting, either on themselves or on a friend. By using crochet and clay modeling or other approaches, kinesthetic learners enhance their visual-spatial understanding of a given organ or structure in relation to the general anatomical landscape and create a 3$\mathrm{D}$ mental picture that is easy to retrieve, which is important when students take the cadaver-oriented practical examination.

Crochet is a technique for creating textiles using a crochet hook plus a variety of different materials such as yarn, crochet thread, fabric, wire, twine, or other innovative materials. Popular projects include Afghans, blankets, hats, and scarves. Some of CMSRU's kinesthetic learners utilize basic stitches to build 3-D anatomical structures stuffed with microfiber filling. In order to create anatomically correct models, they

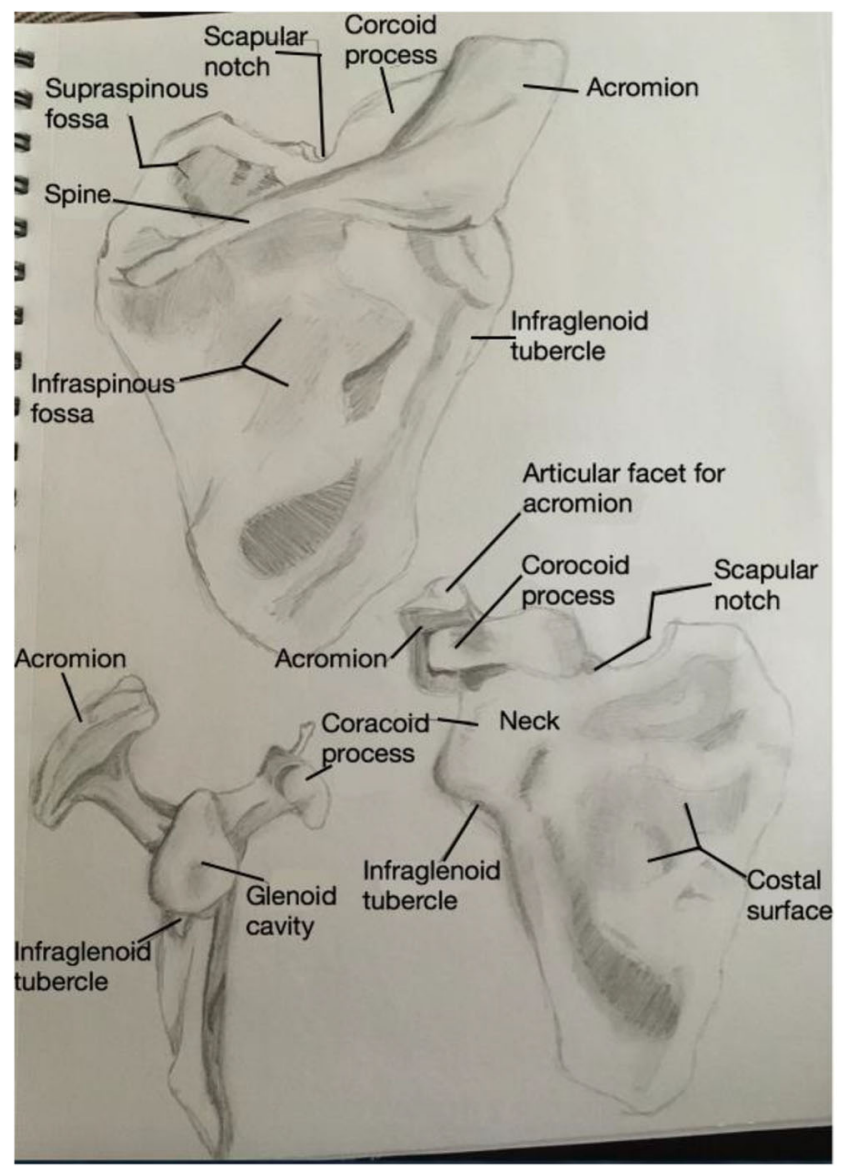

Fig. 1 Schematic drawings of the scapula in various views (dorsal, ventral, and lateral) with anatomical parts identified

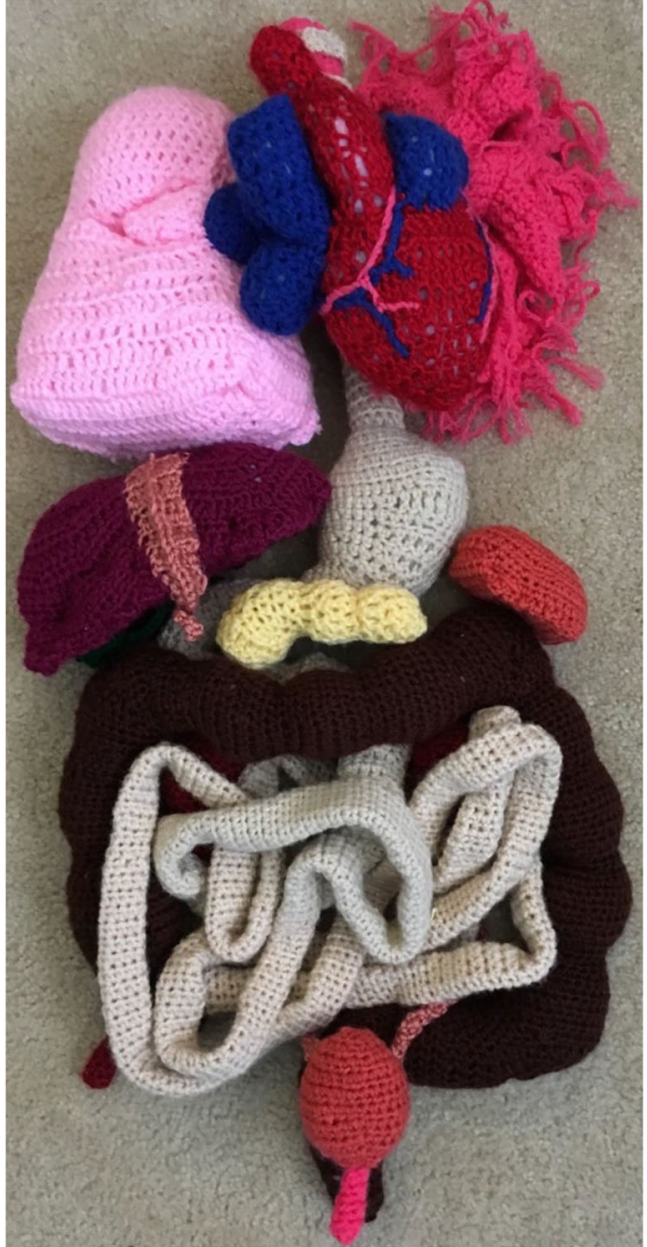

Fig. 2 Crochet models of the thoracic and abdominal gastrointestinal complex progressively achieved while the course of cadaveric dissection was in progress

extensively study the anatomy material presented to them in lectures and small group teaching and they often research other resources to enhance their understanding, as well. The students use the enhanced anatomy knowledge to create 3-D models using crochet and clay models (Figs. 1, 2, and 3) [16]. The experience of creating these crochet models of anatomical structures offers kinesthetic learners a tactile link to the anatomy being taught in the curriculum that they can return to, even after the model is completed. In order to accommodate students with different learning styles and to engage in a cooperative approach, students have unrestricted access to the anatomy laboratory with all the learning aids (cadaver, prosections, and anatomical models, including crochet models), except for those times when practical examinations are scheduled.

Anatomy knowledge is assessed both in multiple-choice question (MCQ) written examinations with clinical vignettes and in the cadaver-oriented practical examinations. To be contextual, practical examinations included student-dissected cadavers, anatomical models, skeletons, and radiological 
Fig. 3 Clay model of the female reproductive system. Coronal view of the uterus, cervix, and vagina are included

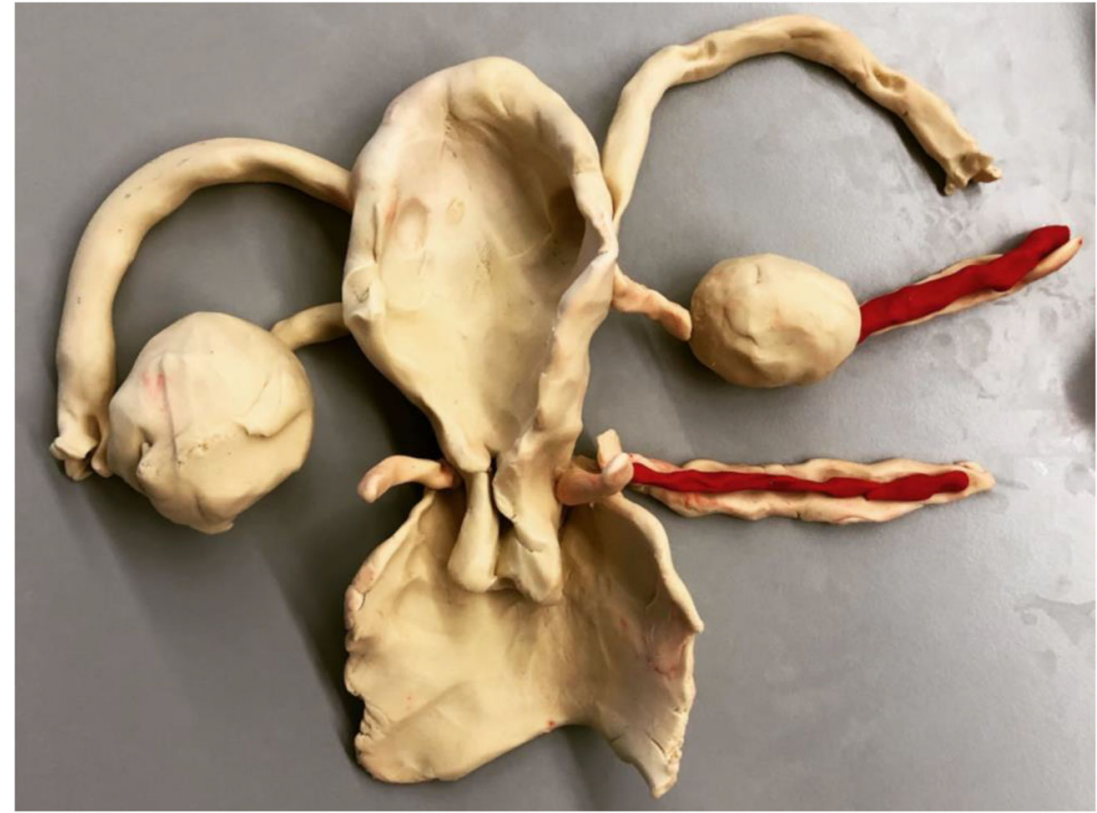

materials used for learning in the anatomy laboratory. Practical examinations include student-dissected cadavers (tag tests), anatomical models, and radiographic images.

By utilizing crochet and clay modeling, kinesthetic learners enhance their visual-spatial understanding of a given organ or structure in relation to general landscape and create a 3-D mental picture that is easy to retrieve. This is important when students take the cadaver-oriented practical examinations, as they must rapidly retrieve stored 3-D mental images.

\section{Discussion}

Ever since Da Vinci's anatomical drawings [17] and publication of Andreas Vesalius' De humani corporis fabrica libri septem [18], art has been a large part of learning anatomy and medicine [19]. Through cadaveric dissection, these masters developed a visual and spatial 3-D relationship to create numerous masterpieces. From a qualitative study of student response to body painting, the authors [20] conclude that body painting can indirectly serve as a teaching tool that focuses on kinesthetic learning, rather than artistic precision or ability.

In medicine, clinical tasks require spatial understanding of anatomy that allow manipulation of structures in the body, especially when performing surgical procedures. When learning anatomy, spatial understanding enhances visual observation, which, in turn, augments retention for later retrieval [21]. Self-directed examination of an object from multiple different perspectives improves spatial learning [22]; this is especially true among kinesthetic learners when they create a clay model or crochet of an anatomical structure they are studying. Rochford [23] observed that medical students who are spatially inept perform poorly in anatomy practical examination and studies conducted since then confirm the observation that a student's spatial ability is an important predictor of success in learning anatomy [21].

Does crochet and clay modeling benefit students in learning anatomy? Does spatial awareness training affect anatomy learning in medical students? [12] In the perspective of the "kinesthetic learners," the answer is affirmative. Each approach has its own preparation. Crochet and clay modeling require 3-D mental image formation that takes into account form, shape, and position in relation to other structures. One makes the mental image by rotating the object to have the spatial orientation and then goes on to produce that mental image into a visual model that transforms into long-term concrete memory of the anatomy. The first author held clay modeling sessions multiple times over a period of 2 years for the underclassmen who were currently studying anatomy. There was a general positive reaction to the sculpting course, as well as to the crochet modeling.

A learning style is a student's consistent way of responding to and using stimuli in the context of learning. Keefe [24] defines learning styles as the "composite of characteristic cognitive, affective, and physiological factors that serve as relatively stable indicators of how a learner perceives, interacts with, and responds to the learning environment." Stewart et al. [25] define learning styles as those "educational conditions under which a student is most likely to learn." Thus, learning styles do not focus on what learners learn, but rather how they prefer to learn.

In observing how kinesthetic learners approach learning anatomy, we learned not to "pigeonhole" learners; medical students use a multimodal approach (visual, aural, reading, and kinesthetic) to master various subject matters and their approaches vary between the preclinical and clinical phases 
of their training [8]. Thus, medical students adopt various learning styles depending upon the "kind of learning" experience they face. Furthermore, learning styles vary depending on whether an examination is important (high stake) or not (low stake). For example, students adopt surface learning for a formative examination and deeper learning for a summative examination. A recent study reported that medical students in general use multimodal approaches in their learning [8]. Medical students change their preferred way of learning, evolving from abstract-reflexive to abstract-active. This change might represent an adaptation to the curriculum, which evolves from a lecture-based, teacher-centered to a problembased, student-centered model. Students creating crochet anatomical models offers evidence of the shift from teachercentered to student-centered; the students create the models from the initial pattern to the final crochet object.

Rather than trying to match learning styles or preferences when teaching anatomy, it is important to provide appropriate learning tools and teaching strategies for all. These strategies include cadaveric dissection, prosection, anatomical study aids (models, including student-created crochet models), small group sessions, and active learning through problem solving $[1,26,27]$. Cadaveric dissection allows teachers to tailor instruction to the learning styles that learners use concentrate on, process, absorb, and retain new and difficult information, meshing teaching tactics with learning style. Though some do not embrace, the meshing hypothesis [4], we find that it has positive effect in anatomy instruction. Through innovative use of crochet, CMSRU students creatively meshed what they learned in dissection, self-directed study, and lecture to deepen their understanding of anatomy through kinesthetic means.

What was the CMSRU student's impression while creating and utilizing crochet and clay modeling? When asked, students responded:

- "Of all the anatomy we had to learn, the pelvic anatomy I remember the best was most likely due to the sculpting course."

- "The course really helped me understand conceptually and spatially the relationship between the muscles, bones, and functions. Taking the time to model the muscles enhanced the learning process, especially since this method of learning went beyond rote memorization. I was able to return to the anatomy lab and teach my group the set of muscles we had focused on in the sculpting course."

- "I enjoyed my time modeling. It was a nice break from the rigors of book studying for an evening and I felt helped me get a better grasp on the anatomy in question, especially some of the larger concepts like specific ligaments etc."

- "Although I am not the best sculptor, I thought that modeling helped solidify the anatomy of the vagina and uterus and helped me feel more prepared for the practical exam."
- "I thoroughly remember the anatomy that I modeled through crochet. I got to go back to the models later and look at them during my surgery rotation and was able to recall the anatomy that I sculpted and applied that knowledge when we were inside someone's abdomen."

The question "does learning style influence academic performance?" is convincingly answered in an earlier [10] and a recent article [28]. Additionally, in support of kinesthetic learners, a recent of article answered the question "does spatial awareness training affect anatomy learning in medical students?" [12].

\section{Conclusions}

Though different learning styles among medical students are discussed this descriptive article primarily focus on a kinesthetic learner's approach to learning anatomy and master the contents delivered in didactic presentations, hands-on cadaveric dissection, small group case-based discussion, and selfdirected directed learning. Using didactic presentations and cadaveric dissections, a kinesthetic learner can study structures and create a 3-D mental model. Kinesthetic learners gain a broader visuospatial understanding of a given organ or structure in relation to general landscape by creating crochet and clay modeling that helps them create a 3-D mental picture that is easy to retrieve. This is important when students take the cadaver-oriented practical examinations, when they must rapidly retrieve stored 3-D mental images.

Acknowledgments It was presented as a poster in the "Anatomy Education-Learning Strategy" session at the American Association of Anatomists EB Annual Meeting, April 2018, San Diego, CA, for which Ms. Hernandez received a travel award from the Society of American Association of Anatomists. The first author, Dr. Jessa Hernandez, would like to thank the support from the Office of Student Affairs at CMSRU and the Travel Award that allowed her to present the materials at the EB American Association of Anatomists annual meeting in 2018.

Assurance The authors assure that the manuscript is an original work, has not been published previously either in whole or in part and is not under consideration for publication by any other journal.

This study involves no human subject. The figures in the manuscript are the original work of the first author and there is no copyright holder involved.

All authors have read and accept responsibility for the manuscript's contents.

Notes on Contributors Jessa E. Hernandez, M.D., B.A., graduated from Cooper Medical School of Rowan University in Camden, New Jersey in Spring of 2020 and started her residency close to our institution. She conducts teaching sessions on clay modeling and other kinesthetic methods for helping kinesthetic learners at Cooper Medical School of Rowan University. She is an aspiring pediatrician.

Cheryl A. Melovitz-Vasan, P.T., D.P.T., Ph.D., is an associate professor of anatomy in the Department of Biomedical Sciences at CMSRU, Camden, New Jersey. She teaches anatomy to the first and second-year medical students, and is involved in interprofessional education. Her 
research interests are anatomy education, assessment, and innovative approaches to anatomy laboratory teaching.

Susan Huff, B.A., is a member of the assessment team and multiple ongoing medical education research projects at CMSRU, New Jersey. She has extensive experience in pedagogical approaches to medical education and curriculum development and is a member of our research team. Her research interests are assessment and evaluation.

Nagaswami S. Vasan, D.V.M., M.V.Sc., Ph.D., is a professor of anatomy in the Department of Biomedical Sciences at CMSRU, Camden, New Jersey. He is the longitudinal course director of anatomy and embryology for first- and second-year medical students and his research interests are in teaching and learning in medicine, assessment, and curriculum development and management.

Funding Information This study was supported in part by internal funds from Cooper Medical School of Rowan University (CMSRU) Research and Innovation Support.

\section{Compliance with Ethical Standards}

Since our study was part of continuing efforts to improve teaching and learning, no IRB approval was required.

Conflict of Interest The authors declare that they have no conflict of interest.

\section{References}

1. Coffield F, Moseley D, Hall E, Ecclestone K. Learning styles and pedagogy in post-16 learning: a systematic and critical review. London: Learning and Skills Research Centre, LSDA; 2004.

2. Fleming ND, Mills C. Not another Inventory, rather a catalyst for reflection. Improve Acad. 1992;11:137-55.

3. Kolb DA. Experiential learning: experience as the source of learning and development. Englewood Cliffs: Prentice-Hall 256 p; 1984.

4. Pashler H, McDaniel M, Rohrer D, Bjork R. Learning styles: concepts and evidence. Psychol Sci Public Interest. 2008;9:105-19.

5. Husmann PR, O'Loughlin VD. Another nail in the coffin for learning styles? Disparities among undergraduate anatomy students' study strategies, class performance, and reported VARK learning styles. Anat Sci Educ. 2019;12:6-19.

6. Kharb P, Samanta PP, Jindal M, Singh V. The learning styles and the preferred teaching-learning strategies of first year medical students. J Clin Diagn Res. 2013;7:1089-92.

7. Entwistle N, Ramsden P. Understanding student learning. London: Croom Helm 266 p; 1983.

8. Samarakoon L, Fernando T, Rodrigo C. Learning styles and approaches to learning among medical undergraduates and postgraduates. BMC Med Educ. 2013;13:42-7.

9. Busan AM. Learning styles of medical students - implications in education. Curr Health Sci J. 2014;40:104-10.
10. Wilkinson T, Boohan M, Stevenson M. Does learning style influence academic performance in different forms of assessment? J Anat. 2014;224:304-8. https://doi.org/10.1111/joa.12126.

11. Magulod GC Jr. Learning styles, study habits and academic performance of Filipino university students in applied science courses: implications for instruction. J Technol Sci Educ. 2019;9(2):184-98. https://doi.org/10.3926/jotse.504.

12. Gonzales RA, Ferns G, Vorstenbosch MATM, Smith CD. Does spatial awareness training affect anatomy learning in medical students? Anat Sci Educ. 2020. https://doi.org/10.1002/ase.1949.

13. Chen D, Zang Q, Deng J, Huang J, Li F, Xiong K. A shortage of cadavers: the predicament of regional anatomy education in mainland China. Anat Sci Educ. 2018;11:397-402.

14. Sugand K, Abraham P, Khurana A. The anatomy of anatomy: a review for its modernization. Anat Sci Educ. 2010;3:83-93.

15. Ghosh SK. Cadaveric dissection as an educational tool for anatomical sciences in the $21^{\text {st }}$ century. Anat Sci Educ. 2017;10:286-99.

16. Hernandez J, Vasan NS. Learning styles among medical students: kinesthetic learners approach to learning anatomy. FASEB J. 2018;32(1):Supplement,508.13.

17. Leonardo Da Vinci Biography (1510). https://www.biography. com/people/leonardo-da-vinci-40396. Biography.com. Accessed 17 Nov 2019.

18. Vesalius A. De humani corporis fabrica libri septem. Basel: Joannes Oporinus; 1543.

19. Bell LT, Evans DJ. Art, anatomy, and medicine: is there a place for art in medical education? Anat Sci Educ. 2014;7:370-8.

20. Finn GM, Mclachlan JC. A qualitative study of student responses to body painting. Anat Sci Educ. 2010;3:33-8.

21. Bulthoff HH, Edelman SY, Tarr MJ. How are three-dimensional objects represented in the brain? Cereb Cortex. 1995;5:247-60.

22. Garg AX, Norman G, Sperotable L. How medical students learn spatial anatomy. Lancet. 2001;357:363-4.

23. Rochford K. Spatial learning disabilities and underachievement among university anatomy students. Med Educ. 1985;19:13-26.

24. Keefe JW. Learning style: an overview. NASSP's Student learning styles: diagnosing and proscribing programs. Reston: National Association of Secondary School Principals; 1979. p. 1-17.

25. Stewart KL, Felicetti LA. Learning styles of marketing majors. Educ Res Q. 1992;15:15-23.

26. Vasan NS, Holland B. Increased clinical correlation in anatomy teaching enhances student's performance in the course and national board subject examination. Med Sci Monit. 2003;9:23-8.

27. Vasan NS, DeFouw D, Holland B. Modified use of team-based learning for effective delivery of medical gross anatomy and embryology. Anat Sci Educ. 2008;1:3-9.

28. Magulod G Jr. Learning styles, study habits and academic performance of Filipino university students in applied science courses: implication for instruction. J Technol Sci Educ. 2019;9:184-98.

Publisher's Note Springer Nature remains neutral with regard to jurisdictional claims in published maps and institutional affiliations. 